\title{
Interactive comment on "Evaluating impacts of climate change on future water scarcity in an intensively managed semi-arid region using a coupled model of biophysical processes and water rights" by Bangshuai Han et al.
}

\section{Anonymous Referee \#1}

Received and published: 29 May 2018

The manuscript analyses how different climate change scenarios can impact water availability for irrigation on the Treasure Valley (USA). The analysis is conducted starting from the outputs of 11 GCMs from CMIP5 run under RCP4.5 and RCP8.5 scenarios, which are bias-corrected and downscaled (by the authors of by others?) and then randomly sampled using a Latin Hypercube Sampling technique to provide a parsimonious input to a stochastic weather generator. The weather generator is then run to produce a number of time series to provide the input to a semi-distributed hydrological model. Finally, water allocated for irrigation and water deficits are estimated by 
comparing the simulated water availability in the stream with biophysical water demand from agriculture lands and water rights.

Although, according to my opinion, the analysis can be of interest for HESS readers, I cannot recommend the publication because the paper requires deep revisions. As a matter of fact, the same information can be conveyed in a much more clear and effective way in about half of the current text. In many parts of the manuscript I found very difficult to understand what the authors have done, and some of my doubts found an answer only after reading many pages. Information is often distributed along the manuscript with repetitions and without any reason for such a fragmentation. Thus I recommend to reject the paper with an invitation to resubmit a deeply revised, concise and more clear manuscript. General and specific comments are provided in the following.

*General comments*

The manuscript need a deep reorganization. I suggest the following actions:

1) Section "2 - Methods" currently includes 6 sub-sections/sub-sub-sections, that are a mixture of models, data and study area description. Description of datasets is split among sections 2.1.2, 2.2, and 2.4, but datasets are not "methods"; description of models and methods is split among sections 2.1.1, 2.2 and 2.3; the study area is described in section 2.5, but again the study area is not a method. I suggest to reorganize the presentation putting together coherent information: e.g. merging the material disseminated in Section 2 into three Sections: "Methods/models", "Study area", "Dataset".

2) Section "4.1 - Adopting stochastic weather generators with GCM output" (within Section 4 "Discussion") is not a discussion! There is nothing new: it is a sequence of well-known and obvious considerations. It can be removed.

3) Section "4.3 - Future work" (within Section 4 "Discussion"), where they declare their plans for the future. It is not a discussion and I suggest to remove the section.

Printer-friendly version

Discussion paper 
4) As a general rule, I suggest the authors to avoid fragmentation of the information since it create confusion and the reader is lost. At the same time, be sure to give as soon as it is possible important information and complete explanation. E.g. I read in the Abstract that the study area is the Treasure Valley, but to discover where it is located I must read the first 19 pages, and even reading the whole paper I did not find the extension of the study area! This is an important information! Other examples are provided as specific comments

5) "Socio-hydrological model" and "Socio-hydrological system". In many part of the manuscript the authors claim they applied a socio-hydrological model/system. I did not find any part of the paper dealing with socio-hydrology, with the exception of Section "4.3 - Future work" (within Section 4 "Discussion"), where they declare that in the near future they will consider also the population and social aspects. I understand that the words "socio-hydrology" are nowadays appealing, but cannot be used in the context of the analysis and methods of this work. Remove any reference to "socio-hydrology"!

*Specific comments*

6) Introduction. There is a long discussion on stochastic weather generators from page 5 to page 7 . At the end of page 7 (line 149) the authors declare they have applied the WXGN model: I would have expected a reference here! Then in Section 2.1.1 (page 8) there is another list of references of stochastic weather generators and finally in page 9 it is declared the model used! This is another example of fragmentation. Please keep the state-of-the-art in the Introduction and then in the section "Methods" describe the used methods! This makes also clearer if the authors are using something developed by them or by others.

7) Section "2.1.2 - Climate change scenario design". There is a lot of confusion here. Under CMIP5 the word "Historical" is used for GCMs runs in the historical period from1850 to 2005 (then extended to 2012) forced by "observed" atmospheric composition changes. In line 207 I read: "1) Historical: This scenario group evaluates a 30-year

Printer-friendly version

Discussion paper

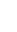


historical period as a baseline". Immediately I annotated "which period?". Again I had to read other two pages and move to Section 2.2 to understand that the authors use the words "historical scenario" to refer to a single station time series at the "Boise Air Terminal weather station from $1980-2014$ ". I suggest to avoid to create confusion using improperly the word "historical scenario". The way it is presented in section 2.1.1 is misleading: "1) Historical ..." in line 207, "2) RCP4.5 ..." in line 209 and "3) RCP8.5" in line 215. Anybody with a basic knowledge of CMIP5 experiments will interpret the first scenario as a run with observed forcing that stops in 2005 (or 2012) and the RCP4.5/ RCP8.5 as run with prescribed radiative forcing starting in 2006 (or 2013) ....

8) Clarify which 30-year period (line 207) is considered for observations and for RCP4.5/ RCP8.5 run. For observations there are contradicting information, e.g. see line 244 (1980-2014, i.e. 35 years), line 390 (1981-2014, i.e. 34 years). For RCP4.5/RCP8.5 it is not clarified.

9) Abstract: lines 28-30. "Three climate change scenario groups ....". Considered climate change scenarios are only 2 : RCP4.5/ RCP8.5. This comment is also related to previous comment \#7.

10) Line 237: "Latin Hypercube Sampling". Put a reference.

11) Line 238: "This data 210 sets ...". Apart for the language, why this "unusual" number? Only reading some other pages I was able to reconstruct where this number come from ...

12) Line 251-253. Why making reference to 20 GCMs if only 11 are used? This create confusion,. just refer to the 11 used.

13) Line 268-272. There is no need to explain how to compute the 25th and 75th percentile in a sample. Specifically this is the Hazen plotting-position formula.

14) Lines 287-288: "the LHS approach equally divides the range of each variable into $\mathrm{M}$ (here, $\mathrm{M}=10$ ) probable intervals". LHS intervals must be "equally probable". Equally 
dividing the range of each variable will produce intervals with different probability. The partition is usually made using the CDF and equally dividing the CDF co-domain $(0,1)$.

15) Line 321. I would have expected to find a reference for HBV.

16) Line 490 and following, Figure 6 and 7: "acre-feet". Please use metric units! This is in general batter, moreover HESS is an European journal. Why not using e.g. $\mathrm{mm} / \mathrm{yr}$ as in Figure 8 and 9, which display the spatial distributions of the same variables?

17) Caption of Figure 6: “.... (Line figure. Show mean, and $85 \%$ and $15 \%$ range for each scenario group)". I do not understand.

18) Legends of Figure 8 and 9 are not readable.

Interactive comment on Hydrol. Earth Syst. Sci. Discuss., https://doi.org/10.5194/hess-2018140, 2018. 